led to the myocardial infarction, and death. Pathological manifestation of cardiac involvement in PN included the left ventricular hypertrophy due to renovascular arterial hypertension in 26 cases (70.3\%). In addition, interstitial myocarditis was observed in 4 cases $(10.8 \%)$.

Conclusions: Our date suggest that cardiac involvement is common in polyarteritis nodosa $(81.1 \%)$, and coronary vasculitis affecting medium and small-sized arteries with wide range of acute and chronic changes can be the life-threatening condition.

Disclosure of Interest: None declared

DOI: 10.1136/annrheumdis-2017-eular.6950

\section{THU0333 ARE THE DEMOGRAPHIC AND CLINICAL FEATURES OF POLYARTERITIS NODOSA SIMILAR BETWEEN THE UK AND TURKEY?}

O. Karadag ${ }^{1,2}$, A. Erden ${ }^{1}$, E.D. Batu ${ }^{1}$, S. Gopaluni ${ }^{2}$, A. Sari ${ }^{1}$, B. Armagan ${ }^{1}$, I. Ertenli ${ }^{1}$, S. Ozen ${ }^{1}$, D. Jayne ${ }^{2} .{ }^{1}$ Hacettepe University Vasculitis Centre, Ankara, Turkey; ${ }^{2}$ Vasculitis and Lupus Clinic Addenbrooke's Hospital, University of Cambridge, Cambridge, United Kingdom

Background: Polyarteritis Nodosa (PAN) is the first described but the least frequent primary systemic vasculitis. Various subgroups of necrotizing vasculitis have separated out from PAN, and are now defined such as HBV-related, cutaneous PAN or monogenic forms of vasculitis. There is a paucity of information on the current phenotypes and, ethnic and geographic differences of PAN.

Objectives: This study compares the demographic and clinical features between two PAN cohorts.

Methods: A retrospective survey of databases from two vasculitis centres between 1990-2016 for PAN patients fulfilling the EMEA Vasculitis Classification algorithm. All paediatric patients met the Ankara 2008 (EULAR/PReS endorsed) criteria for childhood PAN. Patients with typical angiographic and/or histopathologic findings consistent with PAN were included. Demographics, and clinical characteristics, Disease Extent Index (DEI) and Vasculitis Damage Index were recorded. A subgroup analysis based on disease extent between the UK patients with Turkish (TR) patients was performed.

Results: 93 (M/F: 51/42) patients (UK: 47, TR: 46) were recruited into the study. The mean age was $46.7(20.7)$ years. Three were HBV-related, $20(21.5 \%)$ had paediatric onset, $16(16.5 \%)$ were cutaneous PAN.

Turkish patients had younger disease of onset (28.7 (17.8) vs. 43.0 (18.0), $p<0.001)$. Twelve $(26 \%)$ of Turkish patients had a monogenic disease (FMF association in 7, DADA2 in 5).

Cutaneous PAN was more frequent in the UK group (12 pts vs. $4 p t s, p=0.031$ ) whereas renal involvement was increased in the TR group (Table). In contrast to systemic involvement, female predominance was seen in cutaneous PAN $(40.3 \%$ vs. $68.8 \%, p=0.037)$. DEI was similar in both systemic involved groups $(6.1$ (2.4) vs. $6.5(2.3), p=0.428)$. No difference was found between paediatric and adult onset patients except for frequency of cutaneous lesions (100\% vs. $64.3 \%$, $\mathrm{p}=0.002$ ).

During a median 67.5 (32-126) months follow up, 13 patients deceased. No difference was found between the groups regarding relapse rate, death and vasculitis damage index (Table)

Table: Demographic and clinical characteristics of PAN patients

\begin{tabular}{|c|c|c|c|c|}
\hline & $\begin{array}{l}\text { All patients } \\
\mathrm{n}: 93\end{array}$ & $\begin{array}{l}\text { UK cohort } \\
(\mathrm{n}: 47)\end{array}$ & $\begin{array}{l}\text { Turkish } \\
\text { cohort (n: 46) }\end{array}$ & $\mathbf{p}$ \\
\hline Age at time of study & $46.7(20.7)$ & $52.5(19.6)$ & $33.6(17.1)$ & $<0.001$ \\
\hline Age at diagnosis, years & $35.8(19.2)$ & $43.0(18.0)$ & $28.7(17.8)$ & $<0.001$ \\
\hline Time to diagnosis, months & $2(1-6)$ & $2(1-5)$ & $3(2-8)$ & 0.041 \\
\hline Sex, male, \% & 54.8 & 44.7 & 65.2 & 0.047 \\
\hline Any constitutional symptoms, $\%$ & 87.7 & 87.1 & 88.1 & 0.898 \\
\hline Any cutaneous manifestations, $\%$ & 71.7 & 68.1 & 75.6 & 0.426 \\
\hline Musculoskeletal manifestations, \% & 78.0 & 76.7 & 82.6 & 0.278 \\
\hline Neurologic manifestations, $\%$ & 38.8 & 32.5 & 54.3 & 0.089 \\
\hline $\begin{array}{l}\text { Testicular pain/tenderness (men } \\
\text { only), } \%\end{array}$ & 20.3 & 28.5 & 16.7 & 0.310 \\
\hline Renal involvement, $\%$ & 58.0 & 40.4 & 76.1 & $<0.001$ \\
\hline Gastrointestinal manifestations, $\%$ & 47.1 & 48.8 & 45.0 & 0.733 \\
\hline Follow up, months & $67.5(32-126)$ & $79.0(35.0-143.0)$ & $65(29.5-108)$ & 0.669 \\
\hline $\begin{array}{ll}\text { Response to treatment, \% } \\
\text { : } & \text { Complete } \\
\text { Partial } \\
\text { - } & \text { No response } \\
\end{array}$ & $\begin{array}{l}58.5 \\
30.8 \\
10.8\end{array}$ & $\begin{array}{l}60.4 \\
30.2 \\
9.4\end{array}$ & $\begin{array}{l}54.5 \\
31.8 \\
13.7\end{array}$ & 0.838 \\
\hline Any relapse, $\%$ & 57.1 & 58.9 & 52.9 & 0.675 \\
\hline Death, \% & 14.0 & 12.7 & 15.2 & 0.733 \\
\hline VDI & $1(0-1)$ & $1(0-1)$ & $1(0-2)$ & 0.632 \\
\hline
\end{tabular}

Values are labeled as mean (SD or median (IQR 25\%-75\%), VDI: Vasculitis Damage Index

Conclusions: Even though, the Turkish group had a younger disease onset and higher additional monogenic disease; disease extent, relapse rate, death, and damage index were similar in both groups. Among the cutaneous PAN group there was a female predominance. A multi-centre GWAS study could highlight the impact of genetic background on disease presentation and severity.

Disclosure of Interest: None declared

DOI: 10.1136/annrheumdis-2017-eular.5074

\section{THU0334 EVALUATION OF SUBCLINICAL VASCULAR DAMAGE IN PATIENTS WITH POLYMYALGIA RHEUMATICA: A CROSS-SECTIONAL STUDY USING AN INTEGRATED, NON-INVASIVE APPROACH OF COLOR DOPPLER ULTRASOUND AND CARDIO-ANKLE VASCULAR INDEX (CAVI) MEASUREMENT OF ARTERIAL STIFFNESS}

P. Sessa ${ }^{1}$, I.M. Rutigliano ${ }^{1}$, R. Scrivo ${ }^{1}$, V. Silvestri ${ }^{2}$, F. Ciciarello ${ }^{3}$, G. La Torre ${ }^{4}$ F. Conti ${ }^{1}$, R. Priori ${ }^{1}$, C. Alessandri ${ }^{1}$, V. Riccieri ${ }^{1}$, M. Di Franco ${ }^{1}$, B. Gossetti ${ }^{2}$, G. Valesini ${ }^{1} .{ }^{1}$ 1) Department of Internal Medicine and Medical Specialties; ${ }^{2}$ 2) $P$. Stefanini General and Specialist Surgery Department; ${ }^{3}$ 3) Department of

Cardiovascular Science; ${ }^{4}$ 4) Department of Public Health and Infectious Diseases, University of Rome la Sapienza, Roma, Italy

Background: The association of chronic inflammatory rheumatic disorders with an increased risk of vascular disease, especially cardiovascular and cerebrovascular disease, is a consolidated matter, but data on polymyalgia rheumatica (PMR) are still inconsistent.

Objectives: The aim of our cross-sectional study was to investigate the presence of vascular damage in patients with PMR by analyzing subclinical vascular disease through validated, non-invasive cardiovascular disease markers.

Methods: We enrolled patients with PMR diagnosed according to the EULAR classification criteria and, as controls, patients with major cardiovascular risk factors (MCVRF) including hypertension, diabetes, hypercholesterolemia, cigarette smoking, and obesity. In all of them we performed color Doppler ultrasound to evaluate the common carotid intima-media thickness (IMT), the prevalence of carotid artery stenosis and of anterior-posterior abdominal aortic diameter (APAD); we also assessed the cardio-ankle vascular index (CAVI) to measure arterial stiffness and contextually the ankle-brachial index ( $\mathrm{ABI})$ to investigate the presence of lower-extremity peripheral arterial disease.

Results: Forty-eight patients with PMR and 56 with MCVRF were included. Demographic parameters were balanced between groups. A significant increase of IMT $(1.03 \pm 0.23$ vs $0.89 \pm 0.20 ; p=0.02)$, CAVI $(8.59 \pm 1.23$ vs $7.59 \pm 0.93 ; p=0.01)$ and APAD values $(22.03 \pm 4.86$ vs $19.14 \pm 4.65 ; p=0.03)$ was found in PMR patients with respect to MCVRF controls. No differences were reported with regards to the prevalence of carotid artery stenosis or $\mathrm{ABI}$ values between the two groups. No significant correlation between disease duration or duration of glucocorticoid treatment and IMT or CAVI values was found in PMR patients. Results of bivariate analysis showed a significant correlation between IMT and CAVI in both PMR and MCVRF patients $\left(r^{2}=0.845\right.$ and 0.556 , respectively; $\left.p<0.001\right)$.

Conclusions: Our study adds new information on cardiovascular risk in PMR patients, showing an increase in subclinical cardiovascular lesions and paving the way for further studies to define the utility and modality of cardiovascular screening for primary prevention in these patients.

\section{References:}

[1] Hancock AT et al. Risk of vascular events in patients with polymyalgia rheumatica. CMAJ 2014; 186: E495-501.

[2] Shirai $\mathrm{K}$ et al. A novel blood pressure-independent arterial wall stiffness parameter; cardio-ankle vascular index (CAVI). J Atheroscler Thromb 2006; 13101-7.

[3] Masugata $\mathrm{H}$ et al. Cardio-ankle vascular index for evaluating immunosuppressive therapy in a patient with aortitis syndrome. Tohoku J Exp Med 2010; 222:77-81.

Disclosure of Interest: None declared

DOI: 10.1136/annrheumdis-2017-eular.4831

\section{THU0335 ACETYLCHOLINESTERASE IS HIGHLY EXPRESSED IN THE INFLAMED VESSEL WALL OF PATIENTS WITH GIANT CELL ARTERITIS}

P. Therkildsen ${ }^{1}$, B.D. Nielsen ${ }^{1}$, K.K. Keller ${ }^{1}$, T. Steiniche ${ }^{2}$, L.C. Gormsen ${ }^{3}$, I.T. Hansen ${ }^{1}$, E.-M. Hauge ${ }^{1} .{ }^{1}$ Department of Rheumatology; ${ }^{2}$ Department of Histopathology; ${ }^{3}$ Department of Nuclear Medicine and PET Centre, Aarhus University Hospital, Aarhus, Denmark

Background: The temporal artery biopsy (TAB) remains the gold standard in the diagnosis of giant cell arteritis (GCA) and is part of the ACR Classification criteria for GCA. However, TABs are false-negative in $10-60 \%$ of cases [1]. Cellular studies have shown that activated immune cells upregulate the acetylcholinesterase (AChE) expression [2]. If AChE is upregulated in the active GCA vessel wall, it may potentially improve the TAB as a diagnostic tool.

Objectives: To investigate the in-situ expression of acetylcholinesterase (AChE) in the vessel wall of patients with biopsy-positive GCA and compare to non-GCA patients.

Methods: In this histological case-control study, TABs from a total of 24 TABpositive GCA and 44 TAB-negative non-GCA patients (21 patients with a final diagnosis of PMR, 23 patients with other diagnosis) were retrospectively selected from TABs performed between January 2012 and December 2015. A total of 295 TABs were assed for inclusion. Only positive TABs showing clear transmural inflammation were included. Patients treated with $>7$ days of prednisolone prior to the TAB were excluded. Clinical data were obtained from electronic patient records to confirm or dismiss clinical diagnosis. TAB-HE-stains were reviewed by a pathologist with expertise in vasculitis. Immunohistochemical methods were used to determine the AChE expression. The histological inflammation and AChE 